NBER WORKING PAPER SERIES

MONETARY POLICY WITH A CREDIT AGGREGATE TARGET

Benjamin M. Friedman

Working Paper No. $\underline{980}$

NATIONAL BUREAU OF ECONOMIC RESEARCH

1050 Massachusetts Avenue

Cambridge MA 02138

September 1982

The research reported here is part of the NBER's research program in Financial Markets and Monetary Economics. Any opinions expressed are those of the author and not those of the National Bureau of Economic Research. 


\section{MONETARY POLICY WITH A CREDIT AGGREGATE TARGET}

\section{Abstract}

The principal criteria for the selection of an intermediate target for monetary policy are (1) that the target be closely related to the nonfinancial objectives of monetary policy, (2) that it contain information about the future movements of those relevant aspects of the nonfinancial economy, (3) that it be closely connected to the instruments over which the central bank can exert direct control, and (4) that data on it be readily available on a timely basis.

The evidence presented in this paper indicates that, on each of the four criteria considered, total net credit is just as suitable as any of the monetary aggregates to serve as an intermediate target for monetary policy in the United States. As long as the Federal Reserve System continues to use an intermediate target procedure, this evidence is consistent with adopting a two-target framework based on both money and credit, thereby drawing on information from both sides of the public's balance sheet for the set of signals that govern the systematic response of monetary policy to economic events.

Benjamin M. Friedman

Harvard University Littauer Center 127 Cambridge, MA 02138 (617) $495-4246$ 


\section{MONETARY POLICY WITH A CREDIT AGGREGATE TARGET}

Benjamin M. Friedman*

Harvard University

Monetary policy procedures typically have short life spans. Some basic elements endure, of course, but experience suggests that central banks frequently overhaul the specific operating procedures they use to implement monetary policy. These adaptations, which occur at irregular intervals, can be responses to changes in the underlying economic and financial environment, to shifts in policy objectives, or even to advances in economic science. In the United States the past decade or so has been an especially fast-moving period from this perspective. The emergence of rapid and volatile price inflation in the late 1960s had made nominal interest rates, which the Federal Reserve System had emphasized since world war II, clearly less reliable as a focus for monetary policy. ${ }^{I}$ At the beginning of the 1970s, therefore, the Federal Reserve shifted to a policy framework based on monetary aggregates as intermediate targets. ${ }^{2}$ During most of the 1970 s interest rates remained an important part of the policy process, but primarily as the instrument used to influence the growth of the targeted monetary aggregates. In a widely publicized action in October 1979, however, the Federal Reserve abandoned interest rates altogether and adopted new procedures based on controlling the monetary aggregates via the quantity of bank reserves. In the meanwhile, a series of innovations in financial institutions and 
practices during the 1970 s had progressively blurred the meaning of "money." Early in 1980, therefore, the Federal Reserve implicitly changed its operating procedures once again, this time by redefining the monetary aggregates used as the intermediate targets.

As is nearly always the case when central banks change operating procedures, these most recent changes - to a reserves instrument instead of an interest rate instrument, and to new monetary aggregate intermediate targets - have raised new questions and revived old ones. Indeed, as a measure of its own active concern with these questions, the Federal Reserve Board in 1981 published a two-volume study, New Monetary Control Procedures, consisting of thirteen staff papers on various aspects of the subject. Although these studies addressed a broad range of specific topics, the main focus was on the same issues that have always been central to the analysis of monetary policy procedures under an intermediate target strategy: what aggregates to target, what instruments to use to achieve those targets, and what variation of both instruments and intermediate targets to seek (or tolerate) over time. Apparently these basic issues are as open today as they have been at any time in the past.

The object of this paper is to consider the evidence bearing on the most central of these choices determining monetary policy procedures under the intermediate target approach $\longrightarrow$ the selection of the intermediate target itself - and to do so in the context of a specific alternative to the current exclusive reliance on the monetary aggregates. In particular, in a series of recent papers 
(Friedman 1981, 1982a, 1982b) I have documented the stability of the relationship between credit and income in the United States, and have gone on to suggest several implications of this regularity for both monetary and fiscal policies. The chief implication for monetary policy is that the available empirical evidence on the relative stability of the credit-to-income and money-to-income relationships does not support a special role for money over credit in formulating and implementing monetary policy. Since there is nothing special about (inside) money from an a priori perspective either, there is therefore little basis for monetary policy procedures which focus on target growth rates for specific measures of the money stock with little if any attention paid to credit measures. Although a close and reliable relationship to nonfinancial economic activity is perhaps the most important factor determining the suitability of a financial aggregate as an intermediate monetary policy target, it is hardly the only consideration. A second important criterion is that the relationship of an intermediate target to nonfinancial activity must go beyond mere contemporaneous correlation, so that current movements of the target contain information about future movements of the relevant aspects of the nonfinancial economy. A third criterion is that an intermediate target must also be closely related to the instruments under the central bank's direct control - in the United States under current procedures the stock of nonborrowed reserves, or alternatively a short-term interest rate. Finally, a fourth criterion is that data on an intermediate target must be readily available on a timely basis. 
Although special strength in some areas may compensate for weakness in others, gross failure on any one of these grounds would render any variable unsuitable as an intermediate target for monetary policy .

This paper presents evidence for the United States comparing total net credit, the credit aggregate that displays the most stable relationship with income, to the major monetary aggregates on each of these four criteria. Section I reviews and updates the evidence showing that the stability of the credit-to-income relationship is comparable to that of the money-to-income relationship. Section II presents evidence on the degree to which current movements of either credit or money signal future movements of nonfinancial economic activity. Section III turns to the question of whether the Federal Reserve could actually meet predetermined credit growth targets, and presents evidence on the relationship of total net credit and the monetary aggregates, respectively, to nonborrowed reserves and to the federal funds rate. Section IV focuses on the timing and reliability of the available credit data by presenting some preliminary results based on monthly credit series. Section $\mathrm{V}$ briefly summarizes the main conclusions reached in the paper and highlights their implications for monetary policy.

The evidence presented in this paper indicates that, on each of the four criteria considered, total net credit is just as suitable as any of the monetary aggregates to serve as an intermediate target for monetary policy. As long as the Federal 
Reserve continues to use an intermediate target procedure, this evidence is consistent with adopting a two-target framework based on both money and credit, thereby drawing on information from both sides of the public's balance sheet for the set of signals that govern the systematic response of monetary policy to economic events. 
I. The Stability of the Credit-to-Income Relationship ${ }^{3}$

The intermediate target procedure for monetary policy involves specifying some financial variable(s) - in the united States today, the monetary aggregates - to stand as proxy for the real economic targets at which monetary policy ultimately aims, such as economic growth, price stability, employment, and international balance. The result is, in effect, a two-step procedure. The central bank first determines what growth of the intermediate target is most likely to correspond to the desired ultimate economic outcome. It then sets some operating instrument over which it can exert close control - in the United States either a short-term interest rate or, since October 1979, the quantity of bank reserves - so as to achieve that growth rate for the intermediate target itself.

The first, and most obvious, criterion for selecting a suitable intermediate target is that the targeted measure must be closely and reliably related to the nonfinancial objectives of monetary policy. Despite the proven seductiveness of discussions about whether any given monetary aggregate will or will not be within the announced target range on some chosen date, it is important never to lose sight of the simple truth that any such aggregate has no policy significance in and of itself. What matters is the effect of monetary policy on the nonfinancial economy, and intermediate targets not reliably related to that effect have no role at all to play in the monetary policy process. Results based on a variety of methodological approaches consistently indicate that total net credit in the United States - 
that is, the aggregate outstanding indebtedness of all U.S. nonfinancial borrowers - bears as close and as stable a relationship to U.S. nonfinancial economic activity as do the more familiar asset aggregates like the money stock (however defined) or the monetary base. Moreover, in contrast to the familiar asset aggregates, among which there seems to be less basis for choice from this perspective, total net credit appears to be unique in this regard among major liability aggregates. Unlike the asset aggregates, the stability of the relationship for total net credit does not just represent the stability of a sum of stable parts. The U.S. nonfinancial economy's reliance on credit, scaled in relation to economic activity, has shown almost no trend and but little variation since World war II. After falling from 156\% of gross national product in 1946 to $127 \%$ in 1951, and then rising to $144 \%$ in 1960 , total net credit has remained within a few percentage points of that level ever since. (The yearend 1981 level was $143 \%$ ) Otherwise it has exhibited a slight cyclicality, typically rising a percentage point or two in recession years (when gross national product, in the denominator, is weak) and then falling back. Although the individual components of this total have varied in sharply different directions both secularly and cyclically, on the whole they have just offset one another. In brief, the secular rise in private debt has largely mirrored a substantial decline (relative to economic activity) in federal government debt, while bulges in federal debt issuance during recessions have mostly had their counterpart in the abatement 
of private borrowing.

The first four columns of Table 1 summarize the stability of the ratios to gross national product of six financial aggregates - total net credit and five others - by showing the coefficient of variation (standard deviation normalized by mean) for each ratio computed from both annual and quarterly U.S. data over the 1959-80 sample period. ${ }^{4}$ In each case the table shows the coefficient of variation computed from raw data, and also computed from detrended data. Total net credit consistently displays the smallest coefficient of variation among the six aggregates, and by a substantial margin, regardless of whether the data are annual or quarterly, or raw or detrended.

What matters for monetary policy, of course, is not just the absence of a time trend, and not even stability at each individual moment of time, but stability in a dynamic sense. Simple ratios of precisely contemporaneous observations may therefore fail to capture what is important in the relationship among variables that move over time with some general lead or lag pattern between them. The remaining columns of Table 1 present the respective standard errors, coefficients of determination and Durbin-Watson statistics of six estimated regression equations, in each case relating the growth of nominal gross national product to a moving average of the growth of one of the six financial aggregates listed in the table, plus a moving average of a fiscal policy measure. The equations are estimated, using quarterly data for 1959-80, in the familiar form 


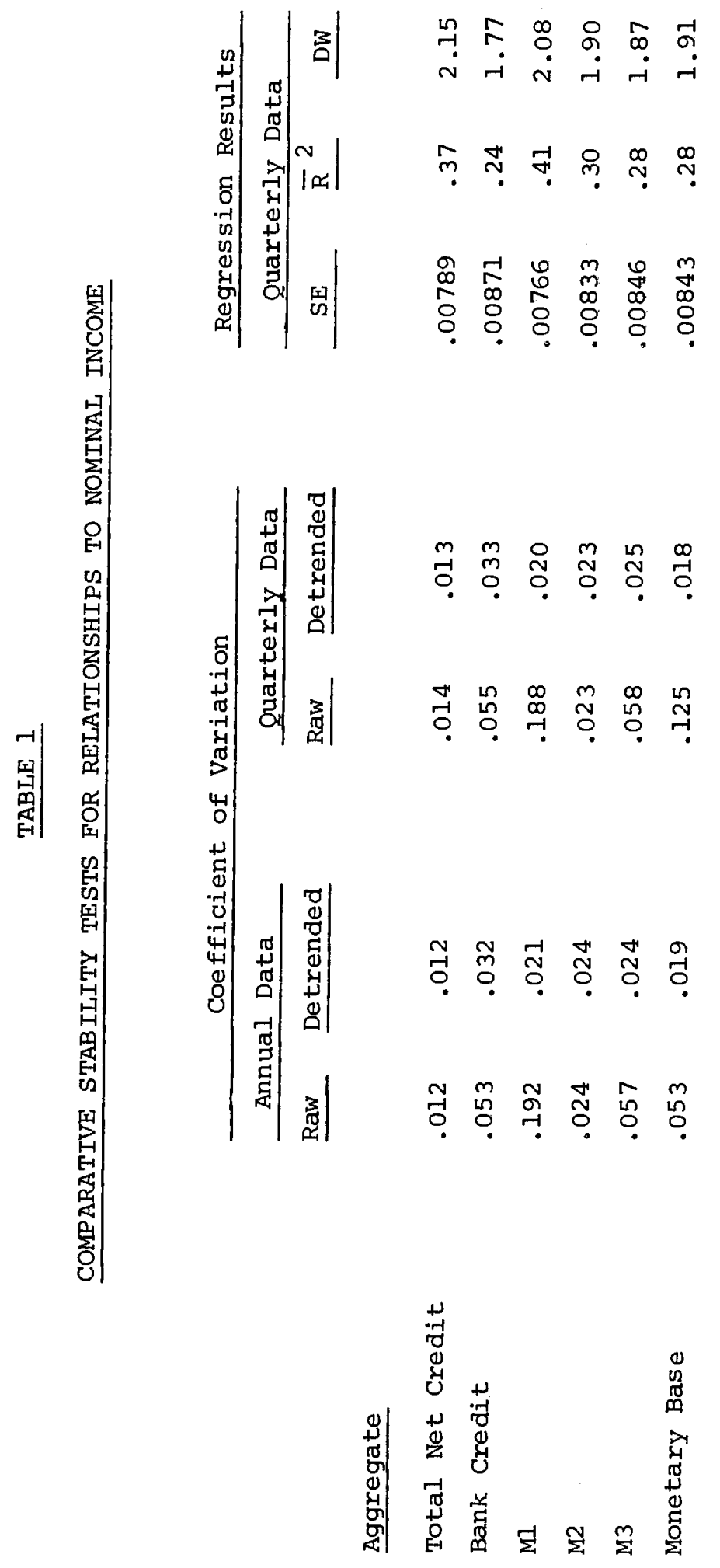




$$
\Delta \mathrm{Y}_{t}=\alpha+\sum_{i=0}^{4} \beta_{i} \Delta \mathrm{F}_{t-i}+\sum_{i=0}^{4} \gamma_{i} \Delta E_{t-i}
$$

where $Y$ is gross national product, $F$ is any of the six financial aggregates, and $\mathrm{E}$ is federal government expenditures calculated on a high employment basis, all expressed in natural logarithms, and $\alpha$, the $\beta_{i}$ and the $\gamma_{i}$ are scalar coefficients, with the $\beta_{i}$ and $\gamma_{i}$ constrained to lie along respective fourth-order polynomials with the implied $\beta_{-1}=\beta_{5}=\gamma_{-1}=\gamma_{5}=0.5$ Here total net credit exhibits a closer relationship to nominal income than does any of the other aggregates except the narrow money stock. 6

In part because of the extent to which regressions of the form (1) have been discredited by a variety of criticisms, researchers examining the money-to-income (or, here, credit-to-income) relationship have increasingly turned to methods that allow for a richer dymamic interaction by relating the variation of income not to the entirety of the variation of money but only to that part of it which cannot already be deduced either from the past history of money itself or from the joint past history of both money and income. $^{7}$ In this context a key indication of the stability of the relationship to income of any financial aggregate is the behavior of that relationship following just such an "innovation," or unanticipated movement, in the aggregate (or in income). A more general representation of (1) that is consistent with this interpretation (but that omits the fiscal variable, so as to keep the order of the system small) is the vector autoregression 


$$
\left[\begin{array}{l}
\mathrm{y}_{\mathrm{t}} \\
\mathrm{F}_{\mathrm{t}}
\end{array}\right]=\left[\begin{array}{l}
\alpha_{1} \\
\alpha_{2}
\end{array}\right]+\left[\begin{array}{ll}
\mathrm{B}_{11} & \mathrm{~B}_{12} \\
\mathrm{~B}_{21} & \mathrm{~B}_{22}
\end{array}\right]\left[\begin{array}{l}
\mathrm{Y}_{\mathrm{t}-1} \\
\mathrm{~F}_{\mathrm{t}-1}
\end{array}\right]+\left[\begin{array}{l}
\mu_{1 t} \\
\mu_{2 t}
\end{array}\right]
$$

where $Y$ and $F$ are again as in (1), the $\mu_{i}$ are disturbances, the $\alpha_{i}$ are fixed scalar coefficients to be estimated, and the $B_{i j}$ are fixed-coefficient lag operator polynomials to be estimated. Solution of the autoregression (2), once it is estimated, yields a moving-average representation of the form

$$
\left[\begin{array}{l}
Y_{t} \\
F_{t}
\end{array}\right]=\left[\begin{array}{l}
\xi_{1} \\
\xi_{2}
\end{array}\right]+\left[\begin{array}{ll}
\theta_{11} & \theta_{12} \\
\theta_{21} & \theta_{22}
\end{array}\right]\left[\begin{array}{l}
\mu_{1 t} \\
\mu_{2 t}
\end{array}\right]
$$

where the $\xi_{i}$ and $\theta_{i j}$ are respectively fixed scalar coefficients and fixed-coefficient lag operator polynomials derived from recursive substitution of the $\alpha_{i}$ and $B_{i j}$ from (2) to express both $Y$ and $F$ as functions of the current values and past histories of both $\mu_{1}$ and $\mu_{2}$, and the normalization convention imposed in estimating (2) constrains the zero-lag elements of the four polynomials in (3) to $\theta_{11}=\theta_{22}=1$ and $\theta_{12}=\theta_{21}=0$ (so that $\mu_{1}$ is "the $Y$ disturbance" and $\mu_{2}$ "the $F$ disturbance"). The orthogonalization of (3) that extracts the independent part of $\mu_{2}$ (say, $\varepsilon_{2}$ ) as "the F innovation" is then just

$$
\left[\begin{array}{c}
Y_{t} \\
F_{t}
\end{array}\right]=\left[\begin{array}{l}
\xi_{1} \\
\xi_{1}
\end{array}\right]+\left[\begin{array}{ll}
\Phi_{11} & \Phi_{12} \\
\Phi_{21} & \Phi_{22}
\end{array}\right]\left[\begin{array}{l}
\varepsilon_{1 t} \\
\varepsilon_{2 t}
\end{array}\right]
$$


where the $\Phi_{i j}$ and the $\varepsilon_{i}$ follow from the $\theta_{i j}$ and the $\mu_{i}$, respectively, and the $\varepsilon_{i}$ are independent. ${ }^{8}$

The upper panel of Table 2 summarizes simulations of (4), estimated in the form (1) using 1959-80 quarterly data for nominal gross national product and each of the six financial aggregates from Table 1 , with eight quarters of lags on each variable in each equation. For convenience the table reports the response of $F / Y$ rather than the individual responses of $F$ and $Y$ separately. Each column in the table presents values, for the initial quarter and then for the final quarter in each of the first five years, indicating the time path followed by $F / Y$ (for the definition of F indicated) in response to a $1 \%$ innovation in $\mathrm{F}^{9}$

Although it is impossible to interpret these simulation results in other than a descriptive way, the responses suggest quite different degrees of dynamic stability among the six aggregateto-income relationships. By construction, $Y$ remains unaffected contemporaneously, so that in the initial quarter each $F / Y$ ratio rises by 1\%. Thereafter the bulge disappears from most of the ratios as $Y$ rises or $F$ declines, or both. The time pattern by which it disappears varies from one aggregate to another, however. The MI money stock ratio quickly returns to (and remains approximately at) the initial base line, and the M2 and total net credit ratios do also, albeit with some delay. By contrast, the bank credit and $M 3$ ratios show little tendency to decline until after two years. The monetary base ratio over-corrects and then remains persistently negative. Overall, MI exhibits the most stable dynamic relationship 


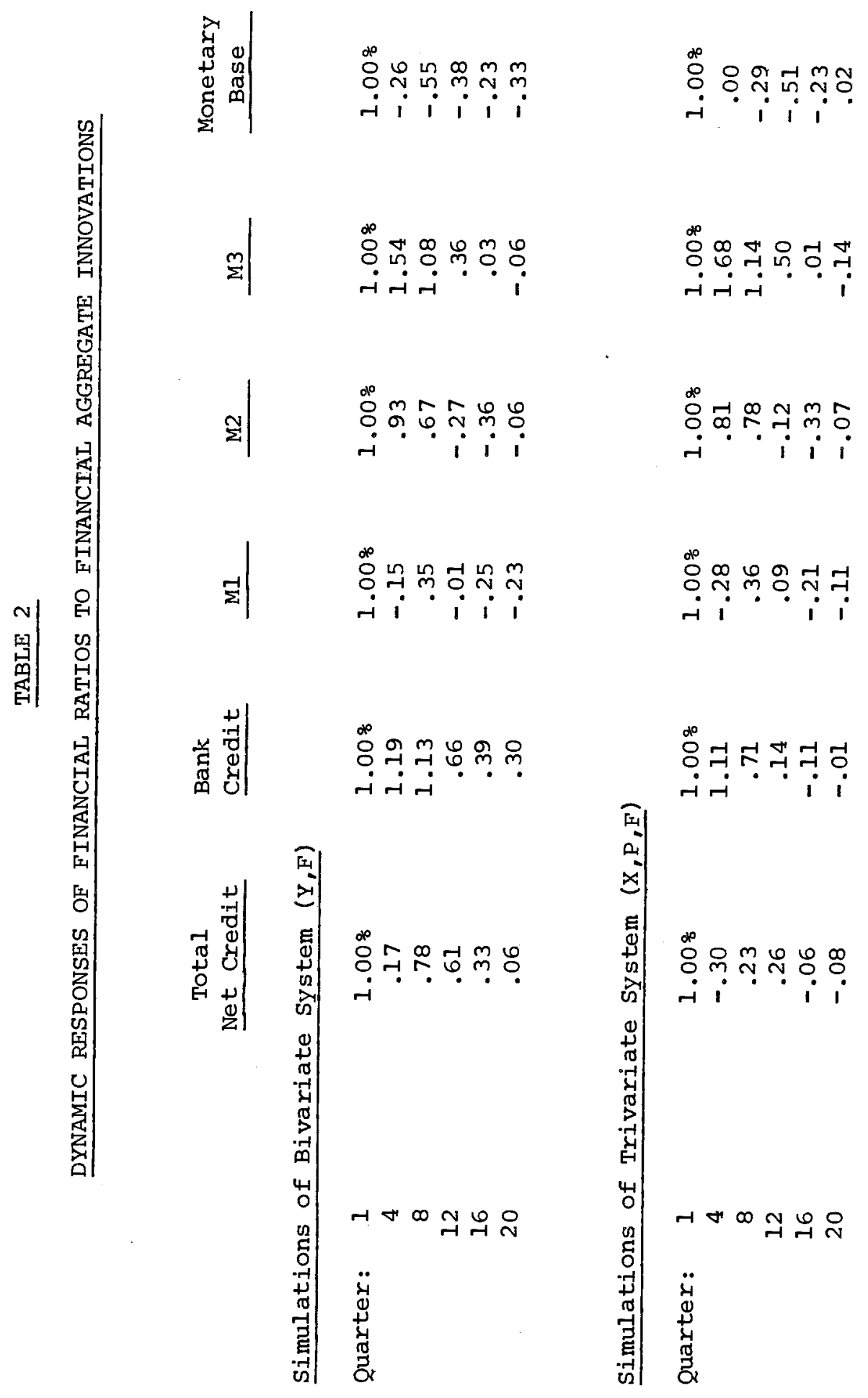


to nominal income in this sense, with $M 2$ and total net credit close behind. ${ }^{10}$

A further aspect of the tendency in recent research to avoid simple nominal income regressions of the form (I) has been a reluctance to ignore the distinction between the real and price components of nominal income variation. The lower panel of Table 2 summarizes simulations that are analogous to those shown in the upper half of the table but based on the moving-average respresentation solved out from the trivariate vector autoregression

$$
\left[\begin{array}{c}
x_{t} \\
P_{t} \\
F_{t}
\end{array}\right]=\left[\begin{array}{c}
\alpha_{1} \\
\alpha_{2} \\
\alpha_{3}
\end{array}\right]+\left[\begin{array}{lll}
B_{11} & B_{12} & B_{13} \\
B_{21} & B_{22} & B_{23} \\
B_{31} & B_{32} & B_{33}
\end{array}\right]\left[\begin{array}{l}
x_{t-1} \\
P_{t-1} \\
F_{t-1}
\end{array}\right]+\left[\begin{array}{l}
\mu_{1} \\
\mu_{2} \\
\mu_{3}
\end{array}\right]
$$

where $\mathrm{X}$ is real gross national product and $\mathrm{P}$ is the price deflator (both in natural logarithms). Here the total net credit and MI ratios are the two that quickly return to, and remain nearly at, the initial base line. Once again, the stability of the total net credit ratio is comparable to that of any of the monetary aggregates. ${ }^{11}$ Finally, it is useful to point out that the stability of the credit-to-income relationship is a phenomenon in no way restricted to the United States in the post World war II period. The U.S. nonfinancial economy's reliance on credit relative to economic activity has shown essentially no trend not just over the past thirty years but over the past sixty. (The 1921 level was 142\%.) Nonfinancial borrowers' outstanding debt rose significantly in relation to gross national product only during 
the depression years 1930-33, when the economy was deteriorating rapidly and many recorded debts had defaulted de facto anyway. Otherwise the postwar stability in the United States appears to be a continuation of a pattern that dates back at least six decades. Among foreign economies, empirical research thus far has demonstrated a similar comparability of the credit-to-income and money-toincome relationships in Britain, Canada, Germany and Japan. In sum, there is ample ground for believing that total net credit, measured by the total outstanding indebtedness of all of the economy's nonfinancial borrowers, is as closely related to nonfinancial economic activity as are the monetary aggregates which are so central to today's monetary policy framework. 
II. The Information Content of Money and Credit

The essence of the intermediate target procedure is that, under it, the central bank is required to respond quickly (and fully) to any information reflected in the movements of whatever the intermediate target happens to be. Under the current framework in the United States, with monetary aggregates used as the intermediate targets, any movement in the public's money holdings therefore creates a presumption that the Federal Reserve System should react. In principle the Federal Reserve is always free to change the money growth targets, of course, but in practice it is typically reluctant to do so. The intermediate target strategy instead calls for actions aimed at regaining the stated targets, so that the economic signals contained in movements of the monetary aggregates create a presumption of immediate response. By contrast, the presumption of this strategy, strictly implemented, is that there will be no response to signals arising from other sources but not reflected in the intermediate targets.

This procedure makes sense only if the relationship of the intermediate target to the nonfinancial objectives of monetary policy is more than just that of a mirror providing a reflection. Targeting a financial aggregate that merely moved in step with nonfinancial activity, without signaling subsequent nonfinancial outcomes, would provide no advantages over directly targeting some aspect of nonfinancial activity itself. ${ }^{12}$ Instead, current movements of the intermediate target must contain information about the future movements of nonfinancial monetary policy objectives. Hence the finding that the credit-to-income relationship is as 
regular and as stable as the money-to-income relationship would be of little interest in a policy context if the economic behavior underlying these results were such that money "causes" income while income in turn "causes" credit, in the sense of causality that, as Granger (1969) and Sims (1972) have shown, corresponds to econometric exogeneity.

Table 3 summarizes the evidence on the interrelationships among money, credit, income and prices, based again on quarterly data for 1959-80. The top panel of the table presents F-statistics for the test of the null hypothesis that all of the eight coefficients in each respective polynomial are zero, in each successive equation in the trivariate autoregression (5) in which the financial aggregate variable is defined as the Ml money stock. The middle panel presents analogous F-statistics for the corresponding trivariate autoregression in which the financial aggregate is total net credit.

These results are not consistent with any simple proposition that money "causes" income while income "causes" credit. If anything, they suggest the opposite. Past credit innovations contain more significant information about the variation of either real income or prices than do past money innovations. Similarly, both real income innovations and price innovations are highly significant in the money equation in the top panel, but only the price innovations are (marginally) significant in the credit equation in the middle panel. Moreover, the corresponding results shown in the bottom panel of the table, for the four-variable analog to (5) 


\begin{tabular}{|c|c|c|c|c|c|}
\hline \multirow[b]{2}{*}{ Estimation } & \multirow[b]{2}{*}{ of } & \multirow[b]{2}{*}{ Autoregressive } & \multirow{2}{*}{$\begin{array}{l}F(P) \\
n(X, P, M)\end{array}$} & \multirow[t]{2}{*}{$F(M)$} & \multirow[t]{2}{*}{$F(C)$} \\
\hline & & & & & \\
\hline \multirow[t]{3}{*}{ Equation: } & $x$ & 65.68 & 1.68 & $1.85 * * *$ & - \\
\hline & $\mathrm{P}$ & .54 & $152.28 *$ & .86 & 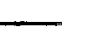 \\
\hline & M & 3.96 & $3.01 *$ & $58.23 *$ & \\
\hline
\end{tabular}

Estimation of Autoregressive System $(\mathrm{X}, \mathrm{P}, \mathrm{C})$

\begin{tabular}{|c|c|c|c|c|c|}
\hline Equation: & $\mathrm{X}$ & $5.10 *$ & $2.73 *$ & $\longrightarrow$ & $2.01 * * *$ \\
\hline & $\mathbf{P}$ & 1.14 & $45.81 *$ & $\longrightarrow$ & $2.50 * *$ \\
\hline & $\mathrm{C}$ & 1.45 & $1.97 * * *$ & - & $66.00 *$ \\
\hline Estimation & of & Autoregressive System & $(X, P, M, C)$ & & \\
\hline Equation: & $\mathrm{X}$ & 5.03 & $2.08 * * *$ & 1.15 & 1.28 \\
\hline & $\mathbf{P}$ & .80 & $27.34 *$ & .60 & $1.98 * * *$ \\
\hline & M & $3.79 *$ & $3.62 *$ & $24.09 *$ & 1.23 \\
\hline & $\mathrm{C}$ & 1.10 & 1.49 & 1.18 & $60.14 *$ \\
\hline
\end{tabular}

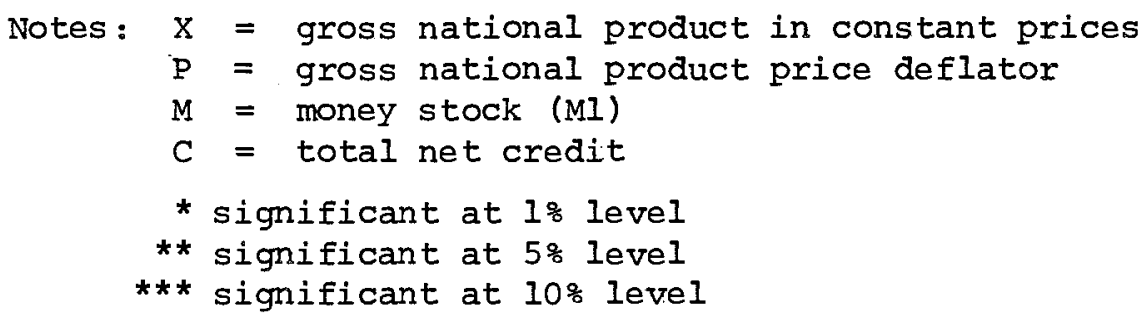


including both money and credit as well as real income and prices, are also inconsistent with any simple money-then-income-then-credit reasoning. ${ }^{13}$

It is also possible to examine in greater generality the extent to which movements of money and credit contain information about the subsequent movements of nonfinancial economic activity. Table 4 presents a dynamic decomposition of the respective variances of real income and prices, based on the moving-average representation of the four-variable autoregression (including both money and credit as well as real income and prices) underlying the bottom panel of Table 3. Specifically, Table 4 shows, for both real income and prices, and for time horizons extending from one quarter to two years, the percentage of variance accounted for by innovations in each of the four variables in the system (including, of course, the variable under study itself)..$^{14}$ Because the results of a variance decomposition (unlike the exogeneity test results presented in Table 3) clearly depend on the ordering imposed in orthogonalizing the moving-average system, ${ }^{15}$ the table presents corresponding sets of results for four different orderings: for the two financial aggregates ordered either before or after real income and prices, and for money ordered either before or after credit within the pair of financial variables.

The variance decomposition results shown in Table 4 indicate that the comparisons based on statistical significance in Table 3 generally carry over to comparisons based on quantitative significance. When ordered first, the financial aggregates together account for 


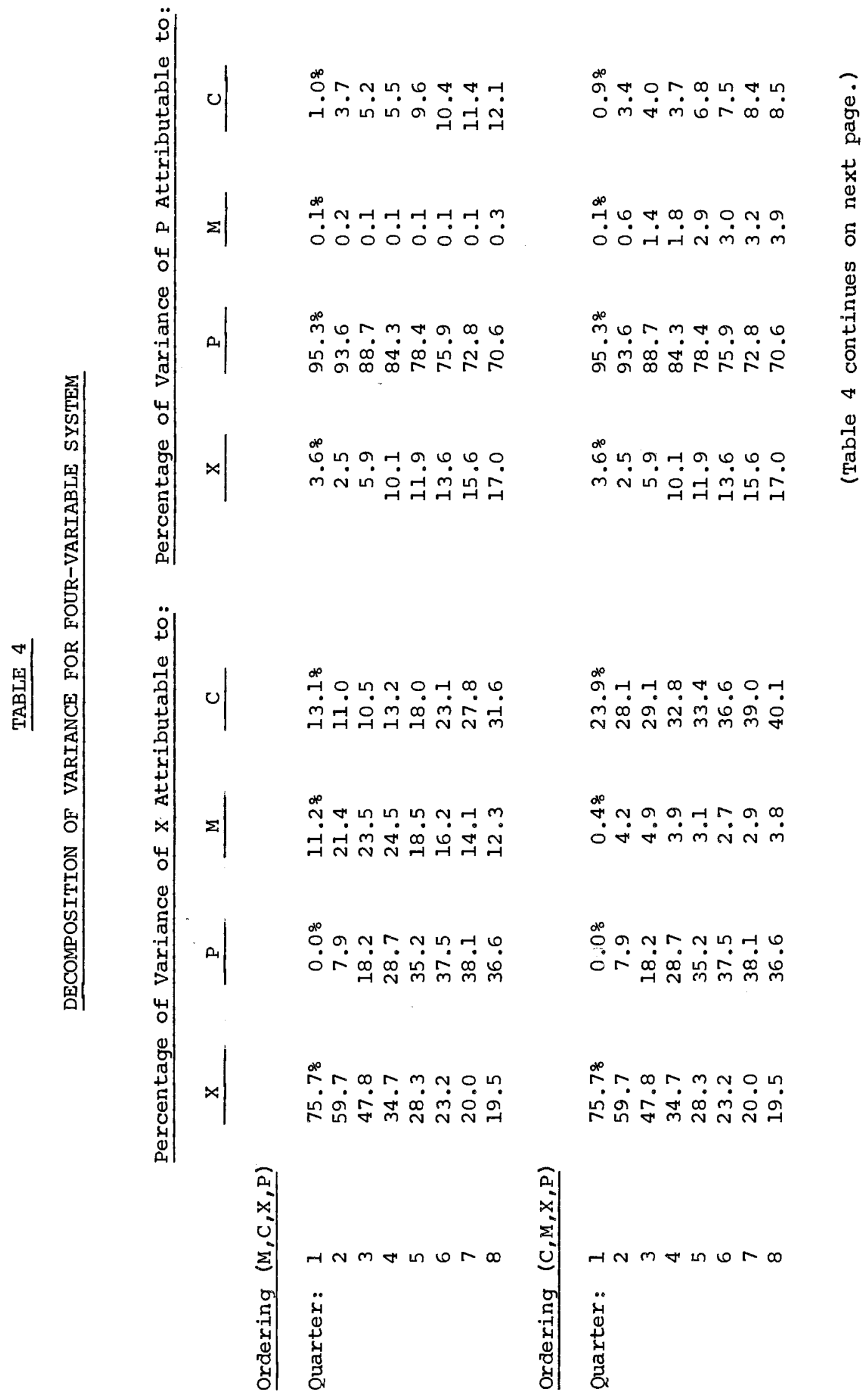




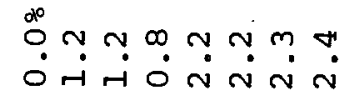

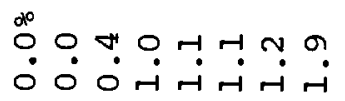

ழீ

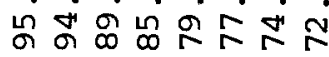

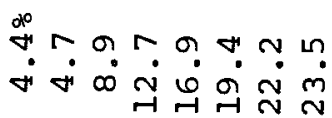

○ீำ

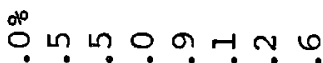

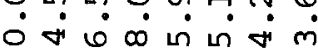

do

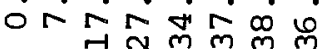

คొ

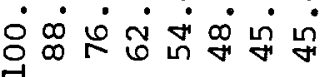

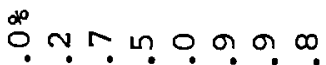
$\dot{0} \dot{0} \dot{0} \dot{0}-\dot{0} 0 \dot{0} 0 \dot{0}$

of n $\dot{0}-\dot{0} \dot{\circ} \dot{\sim} \dot{\sim} \dot{N}$

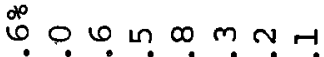

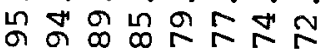

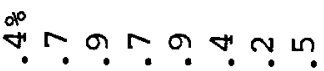
$\dot{\forall} \dot{\sim} \dot{\sim} \dot{\sim} \dot{\sim} \dot{\sim} \underset{\sim}{\sim} \stackrel{\sim}{\sim}$

○ْ m

舟

$\stackrel{0}{0}_{0}$

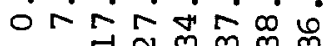

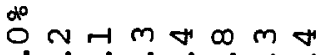

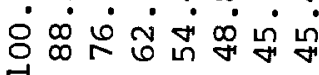


one-third or more of the variance of real income after the initial quarter. If money is ordered before credit, the division between the two aggregates depends on the time horizon, with money appearing more important than credit for a year, and vice versa thereafter. By contrast, if credit is ordered before money, it appears more important throughout. When ordered after the nonfinancial variables, the financial aggregates together account for less of the variance of real income, in a pattern that slowly builds toward one-fifth of the total. The division between money and credit again depends on the time horizon if money is ordered before credit, and again favors credit throughout if credit is ordered before money. One surprising aspect of these results is that the two financial variables together consistently account for a smaller fraction of the variance of prices than of real income. When the financial aggregates are ordered first, that share barely exceeds one-tenth, even after two years. When the financial aggregates are ordered after real income and prices, the corresponding share is almost negligible. Within these smaller amounts, credit usually (but not always) accounts for more of variance of prices than does money.

Because these results change importantly according to not just the ordering among the variables but also the sample period used, it would be unwise to rely heavily on them in any very specific way. ${ }^{16}$ A conservative interpretation of the results presented in Tables 3 and 4 is to conclude that current movements of financial aggregates do contain information, which is at least 
potentially of quantitative importance, about future movements of nonfinancial economic activity, and that the information about nonfinancial activity contained in total net credit is at least comparable to that contained in the narrow money stock. More generally, yet another mode of analysis that potentially could indicate a more important role for money than for credit as an intermediate target variable does not do so. 
III. Controlling Money and Credit

The criteria that determine the suitability of any financial variable as an intermediate target for monetary policy include a relationship not only to the nonfinancial objectives of policy but also to the operating instruments that the central bank can control directly - in the U.S. context, once again, either reserves or a short-term interest rate. For example, although common stock prices in the United States are a well known leading indicator of business activity, there is little evidence to suggest that the Federal Reserve could exert sufficiently close control over the stock market to make it a good monetary policy target. ${ }^{17}$ There would be little point in having an intermediate target that the central bank could not expect to affect reasonably closely, within some plausible time horizon (like a calendar quarter or a half-year) determined by considerations of what matters for the economy as well as what provides political accountability. ${ }^{18}$ The broader the scope of any financial aggregate - on either the asset or the liability side of the economy's balance sheet - and the greater the variety of institutions and individuals involved in supplying and demanding it, the more problematic at the a priori level is the connection between that aggregate and the instruments under the central bank's direct control. Even in the case of the narrow money stock, the number and complexity of the linkages relating its movements to movements of reserves (or the monetary base) are fairly burdensome at either the analytical or the operational level. ${ }^{19}$ This problem is likely to be more 
severe for the broader monetary aggregates; and, at least in principle, total net credit could turn out to be even harder to relate to reserves than M2 or M3. In the end, however, the potential controllability of any such aggregate, either narrow or broad, depends on a diverse set of substitution responses characterizing the behavior of many different kinds of individual and institutional portfolios.

The top panel of Table 5 provides summary statistics for the estimation, using quarterly data for 1959-80, of the relationship

$$
\Delta F_{t}=\alpha+\sum_{i=I}^{4} \beta_{i} \Delta y_{t-i}+\sum_{i=1}^{4} \gamma_{i} r_{D, t-i}+\sum_{i=0}^{4} \delta_{i} \Delta R_{t-i}
$$

where $F$ and $Y$ are again as in (2), $r_{D}$ is the Federal Reserve discount rate, $R$ is the natural logarithm of the quantity of nonborrowed reserves (adjusted for changes in reserve requirements), and $\alpha$, the $\beta_{i}$, the $\gamma_{i}$ and the $\delta_{i}$ are scalar coefficients with the three sets of distributed lag coefficients constrained to lie along respective third-order polynomials with the implied $\dot{\beta_{5}}=\gamma_{5}=\delta_{5}=0.20$ The equation for the credit aggregate (again total net credit) performs better on an overall basis than does that for any of the three monetary aggregates. The credit equation has a quarterly standard error of $0.4 \%$, or $1.4 \%$ per annum. By contrast, the MI and M2 equations both show standard errors of $2.5 \%$ per annum, and the M3 equation's standard error is $2.6 \%$ per annum. 21

It is always possible, of course, that a close overall fit in a relationship like (6) may reflect only the closeness of 
FINANCIAL AGGREGATE CONTROL RELATIONSHTPS: QUARTERLY DATA

$\underline{\mathrm{SE}} \quad \underline{\overline{\mathrm{R}}^{2}} \quad \underline{\mathrm{DW}}$

Reserves Instrument

$\begin{array}{clccr}\text { Aggregate }: \text { Credit } & .00360 & .58 & 1.17 \\ \text { MI } & .00614 & .26 & 1.77 \\ \text { M2 } & .00619 & .34 & 1.20 \\ \text { M3 } & .00651 & .35 & .89\end{array}$

Reserves Instrument with Lagged Dependent Variable

$\begin{array}{clll}\text { Aggregate : Credit } & .00280 & .74 & 2.05 \\ \text { M1 } & .00612 & .26 & 2.00 \\ \text { M2 } & .00538 & .50 & 1.81 \\ \text { M3 } & .00519 & .58 & 1.95\end{array}$

Interest Rate Instrument

$\begin{array}{cccr}\text { Aggregate : Credit } & .00356 & .59 & 1.13 \\ \text { M1 } & .00628 & .22 & 1.59 \\ \text { M2 } & .00477 & .61 & 1.17 \\ \text { M3 } & .00701 & .24 & .63\end{array}$

Interest Rate Instrument with Lagged Dependent Variable

$\begin{array}{clcc}\text { Aggregate : Credit } & .00275 & .75 & 2.09 \\ \text { M1 } & .00610 & .27 & 2.04 \\ \text { M2 } & .00407 & .72 & 2.02 \\ \text { M3 } & .00489 & .63 & 2.03\end{array}$


the aggregate's relation to income, without any implication at all of a connection to the reserves instrument. The top two panels of Table 6 show the full sets of estimated coefficients for the credit and Ml equations summarized in the top panel of Table 5 . Although credit is more closely related to the income terms in the equation than is MI, as a comparison of the t-statistics on the respective $\beta$ values and their sum indicates, it is not the case that credit lacks any connection to the reserves instrument. A comparison of the t-statistics on the respective $\delta$ values shows that the connection to reserves is somewhat weaker for credit than for Ml, but significant nonetheless. ${ }^{22}$

Except for the case of MI, the Durbin-Watson statistic for each of the estimates of (6) shown in the top panel of Table 5 indicates significant serial correlation in the residuals. The second panel of the table shows corresponding summary statistics for the expanded relationship

$$
\Delta F_{t}=\alpha+\sum_{i=1}^{4} \beta_{i} \Delta y_{t-i}+\sum_{i=1}^{4} \gamma_{i} r_{D, t-i}+\sum_{i=0}^{4} \delta_{i} \Delta R_{t-i}+\sum_{i=1}^{4} \theta_{i} \Delta F_{t-i}
$$

including a distributed lag (estimated analogously to the others) on the lagged dependent variable. To the extent that recent movements of an aggregate contain information that the Federal Reserve can use in setting the growth of nonborrowed reserves so as to achieve the targeted growth for that aggregate, (7) is a more reliable guide than (6) to the accuracy to be expected on a quarter-toquarter basis. Although the standard error of each equation in the form (7) is smaller than for (6), that for credit (now only 


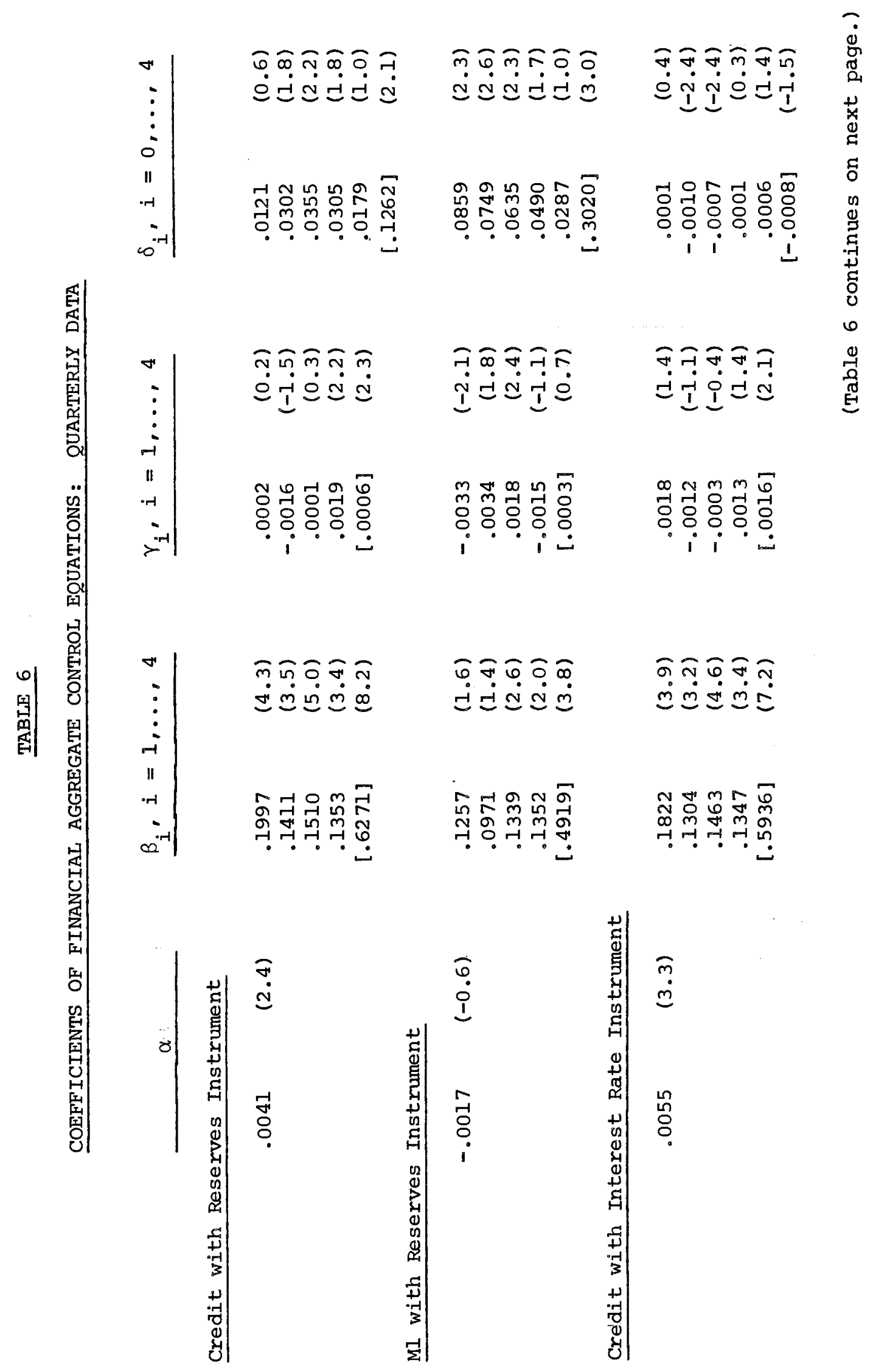


ติวิธยิต

نَ

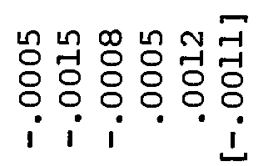

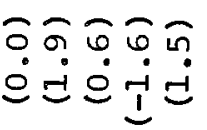

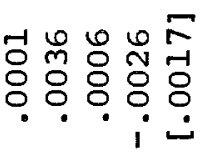

ติำกิ

$\dot{્} \doteq \dot{\bigcup}$

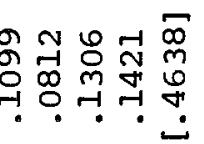
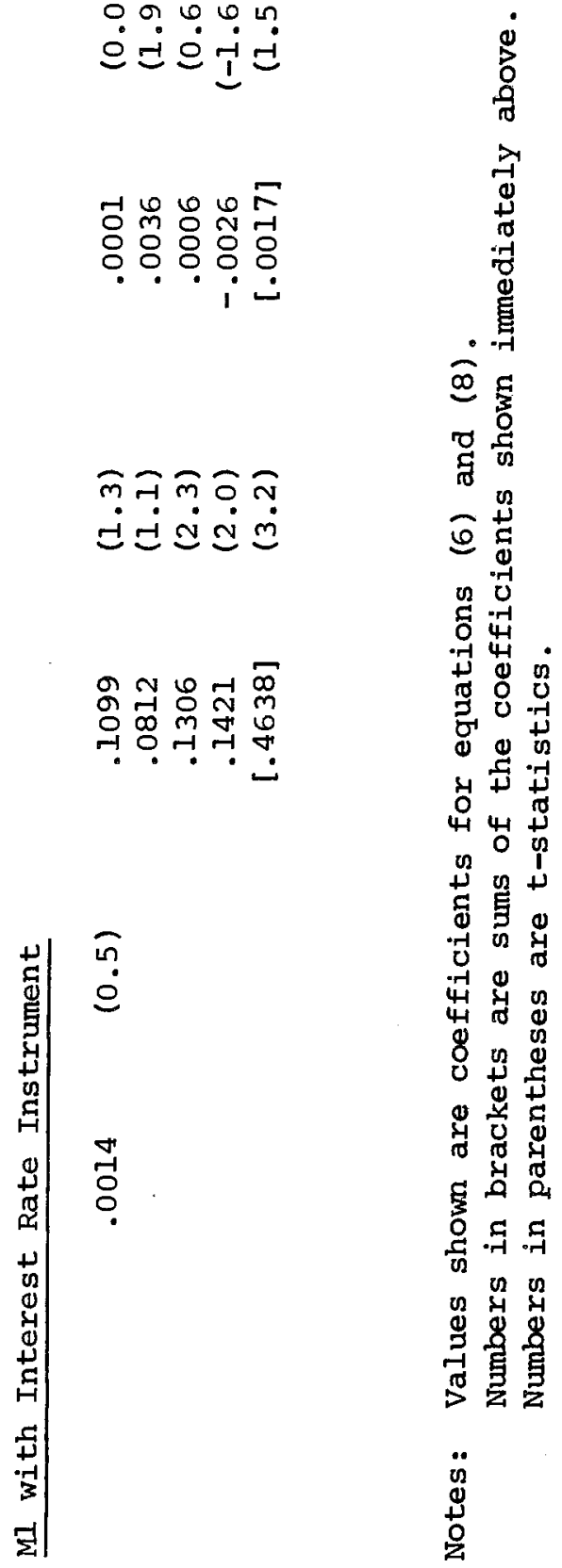
$1.1 \%$ per annum) is still by far the smallest.

The Federal Reserve System has used the quantity of nonborrowed reserves as its operating instrument since october 1979, but there is no assurance that it will always do so. ${ }^{23}$ Hence it is useful to know whether the results found by estimating (6) and (7) carry over to an alternative choice of instrument. The final two panels of Table 5 present corresponding summary statistics for estimating, again using quarterly data for 1959-80, the analogous relationships

$$
\begin{aligned}
& \Delta F_{t}=\alpha+\sum_{i=1}^{4} \beta_{i} \Delta Y_{t-i}+\sum_{i=1}^{4} \gamma_{i} r_{D, t-i}+\sum_{i=0}^{4} \delta_{i} r_{F, t-i} \\
& \Delta F_{t}=\alpha+\sum_{i=1}^{4} \beta_{i} \Delta Y_{t-i}+\sum_{i=1}^{4} \gamma_{i} r_{D, t-i}+\sum_{i=0}^{4} \delta_{i} r_{F, t-i}+\sum_{i=1}^{4} \theta_{1} \Delta F_{t-i}
\end{aligned}
$$

in which the instrument variable is $r_{F}$, the federal funds rate. Although the specific results vary somewhat in comparison to those shown in the two panels above, the superior performance of the equation for total net credit continues as before, with standard errors again equal to $1.4 \%$ and $1.1 \%$ per annum without and with the lagged credit values, respectively.

The final two panels of Table 6 show the full sets of coefficients estimated for (8) using total net credit and Ml as the financial aggregate. Here the t-statistics on the estimated $\delta$ values show that the connection between credit and the federal funds rate instrument is somewhat more significant than that for Ml - just the opposite of the case shown above for the reserves 
instrument. Even so, the t-statistics on the respective coefficient sums are small (in absolute value) for both credit and $\mathrm{Ml} .^{24}$

The overall conclusion suggested by this evidence on the quarterly relationships is that the connection between total net credit and either a reserves or an interest rate monetary policy instrument is roughly comparable to the relationship for the monetary aggregates. 
IV. Using Monthly Data on Money and Credit

The analysis in Section III in effect proceeds as if the Federal Reserve System, in seeking to control its money and/or credit growth targets over a calendar quarter, would decide on the growth of nonborrowed reserves (or the level of the federal funds rate) at the beginning of that quarter and then take no further action until the beginning of the next quarter. Such a procedure would be sensible only if data describing the withinquarter movements of money and credit were either not available at all or were sufficiently "noisy" to be useless. In fact, data on both money and credit are available on at least a monthly basis (weekly for Ml). The noisiness of these short-run data, as indicated by subsequent revisions, is well known (especially for the weekly MI series); but there is no reason to believe that the incoming monthly data are so poor as to be of no use at all in making within-quarter adjustments. 25

Although the standard vehicle in which the Federal Reserve System publishes data on the total net credit aggregate is the flow-of-funds accounts, a publication which appears only once per quarter, the great bulk of the underlying data is actually a available monthly. Indeed, the Federal Reserve currently maintains, on an unpublished basis, a monthly credit data file. As of yearend 1980, the total net credit measure for the United States was $\$ 3,907.5$ billion, of which $\$ 3,436.1$ billion, or $88 \%$, consisted of items regularly reported each month and included in the Federal Reserve's monthly data file. Somewhat ironically, many of the items 
not included in this monthly data file represent the lending activities of various components of the federal government itself. 26 Of the $\$ 471.4$ billion of 1980 yearend total net credit not included in the monthly data file, $\$ 290.7$ billion represented credit advanced directly by the U.S. Government or by its sponsored credit agencies and mortgage pools. If the Federal Reserve were merely to collect from the relevant agencies of the federal government the kind of data it already has on the private sector, therefore, more than $95 \%$ of the total net credit aggregate would be available monthly.

Even without any extra data reporting on the government's part, however, the information contained in the $88 \%$ of total net credit which is currently included each month is hardly without value for monetary policy. For the 1963-77 sample period (the longest interval for which seasonally adjusted credit series now exist in the Federal Reserve's monthly data file ${ }^{27}$ ), the correlation between the total net credit series reported in the flow-of-funds accounts and the quarterly "total" net credit series formed by using only the end-of-quarter months of the corresponding monthly series is .99985 . Moreover, the relationship between nonfinancial economic activity and this quarterly "total" net credit series is fully comparable to that shown for the actual total net credit series in section $I^{28}$

Table 7 presents summary statistics for monthly analogs to the quarterly relationships (6) and (8) in the form 
TABLE 7

FINANCIAL AGGREGATE CONTROL RELATIONSHIPS: MONTHLY DATA

$\underline{\mathrm{SE}} \quad \underline{\overline{\mathrm{R}}^{2}} \quad \underline{\mathrm{DW}}$

Reserves Instrument

$\begin{array}{cccr}\text { Aggregate: Credit } & .00221 & .14 & 1.80 \\ \text { M1 } & .00326 & .12 & 2.02 \\ \text { M2 } & .00269 & .34 & .94 \\ \text { M3 } & .00295 & .29 & .84 \\ \text { Interest Rate Instrument } & & & \\ \text { Aggregate: Credit } & & & \\ & & & \\ \text { M1 } & .00208 & .24 & 2.01 \\ \text { M2 } & .00327 & .11 & 1.99 \\ \text { M3 } & .00213 & .59 & 1.24 \\ & .00290 & .31 & .79\end{array}$




$$
\begin{aligned}
& \Delta F_{t}=\alpha+\sum_{i=1}^{6} \beta_{i} \Delta s_{t-i}+\sum_{i=1}^{6} \gamma_{i} r_{D}, t-i+\sum_{i=0}^{6} \delta_{i} \Delta R_{t-i} \\
& \Delta F_{t}=\alpha+\sum_{i=1}^{6} \beta_{i} \Delta s_{t-i}+\sum_{i=1}^{6} \gamma_{i} r_{D, t-i}+\sum_{i=0}^{6} \delta_{i} \Delta r_{F}, t-i
\end{aligned}
$$

estimated using monthly data for the 1963-77 sample, where $S$ is the natural logarithm of total sales in manufacturing and trade, and the three sets of distributed lag coefficients are constrained to lie along respective fourth-order polynomials with the implied $\beta_{7}=\gamma_{7}=\delta_{7}=0.29$ The standard errors are comparable to or smaller than those shown for the quarterly equations in Table 5, but the coefficients of determination are smaller (as is to be expected). ${ }^{30}$ once again, the equations for the credit aggregate exhibit the smallest standard error $(2.7 \%$ per annum and $2.5 \%$ per annum with the reserves and interest rate instruments, respective$1 y)$, although M2 is a very close second with the interest rate instrument. At least for credit and MI, the Durbin-Watson statistics do not show evidence of significant serial correlation. Table 8 shows the full sets of coefficients for the credit and Ml equations, and here it is apparent from the estimated $\delta$ values (and the associated t-statistics) that the relationship of neither aggregate to plausible policy instruments is well defined on a monthly basis. ${ }^{31}$ Much further work clearly remains to be done in developing monthly credit relationships that would be of potential use for conducting monetary policy, including in the first instance the inclusion of current seasonally adjusted credit data. ${ }^{32}$ Nevertheless, these preliminary results suggest that the available monthly credit 


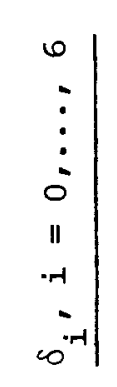

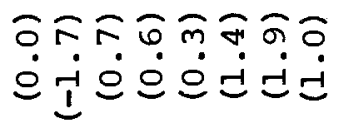

๓ำกำสำ

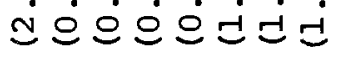

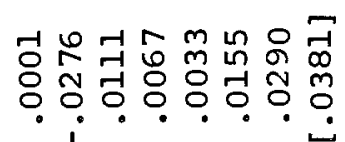

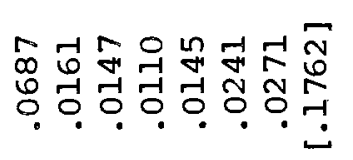

0
0
0
0
0
0
0
0

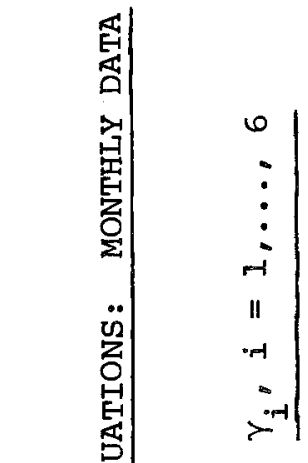

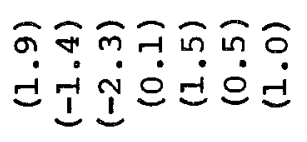

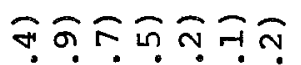

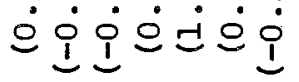

ธี

㘣

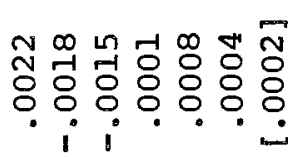

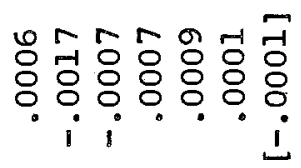

กิธิธิธิธิ

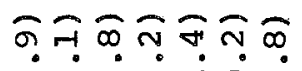

$\dot{\imath} \dot{d} \dot{0} \dot{i} \dot{1}$

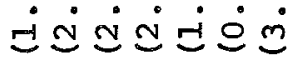

궉ํำ

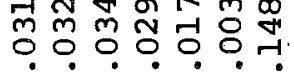

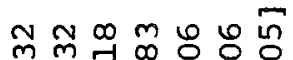

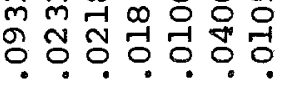

|

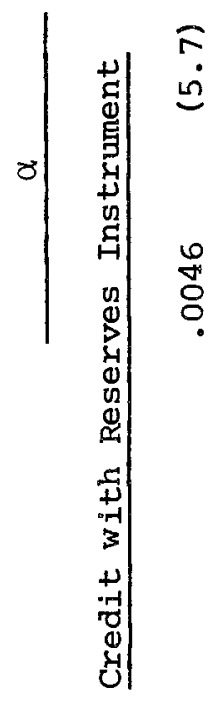

ลุ

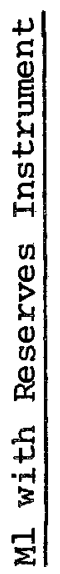



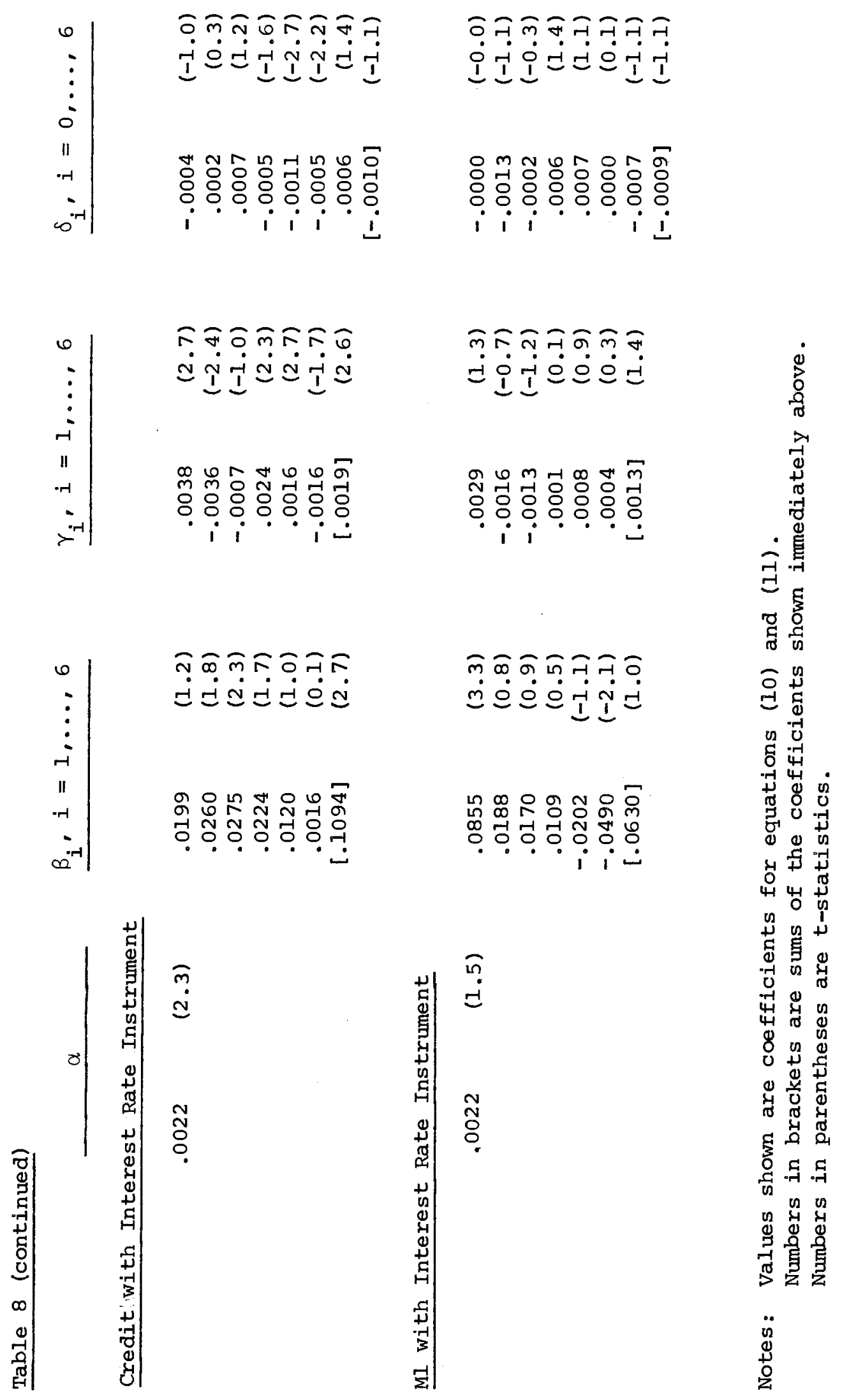
data (even without the missing U.S. Government reports) are sufficiently comparable to the monthly monetary aggregate data to permit the Federal Reserve to take account of a target based on either one more than just once per quarter. 


\section{v. Summary of Conclusions}

The principal criteria for the selection of an intermediate target for monetary policy are (1) that the target be closely related to the nonfinancial objectives of monetary policy, (2) that it contain information about the future movements of those relevant aspects of the nonfinancial economy, (3) that it be closely connected to the instruments over which the central bank can exert direct control, and (4) that data on it be readily available on a timely basis.

The empirical evidence considered in this paper supports a positive conclusion - at least in comparison with the major monetary aggregates - about the potential use of total net credit as an intermediate target variable on each of these four criteria. First, the relationship between total net credit and aggregate measures of nonfinancial economic activity, judged by several different methodological approaches, is as stable and reliable as the corresponding relationship for any of the monetary aggregates (or the monetary base). Second, dynamic analysis based on exogeneity tests and decomposition of variance shows that the information about subsequent movements in nonfinancial activity contained in total net credit is at least comparable to that contained in the Ml money stock. Third, relationships between total net credit and either the quantity of nonborrowed reserves or the federal funds rate are roughly comparable to the corresponding relationships for the principal monetary aggregates. Finally, data for a close approximation to total net credit are available on a monthly basis, 
and the relevant relationships based on the monthly data are also roughly comparable to the corresponding relationships for the monetary aggregates.

These conclusions consistently support the use of total net credit as an intermediate target for monetary policy, either together with or instead of one of the monetary aggregates as long as the Federal Reserve System continues to operate within the intermediate target framework. It is important to note explicitly, however, that the interpretation of empirical results throughout this paper is entirely relative in context. The essential question asked, in each case, is whether or not total net credit meets a specific criterion at least as well as any or all of the more familiar monetary aggregates, and in each case the answer is yes. These results therefore bear importantly on what intermediate targets the Federal Reserve should use, as long as it uses any at all; but they leave open the more fundamental question of whether the intermediate target framework itself is the best way to conduct monetary policy in the current environment. 


\section{Footnotes}

* I am grateful to Richard Clarida for research assistance and many helpful discussions; to Robert Rasche, Carl Christ and other conference participants, as well as to stephen Taylor, for useful comments on an earlier draft; and to the National Science Foundation (grant SES8I-12673) and the Alfred P. Sloan Foundation for research support.

1. In the early post-war years, the Federal Reserve was obligated to peg bond prices. After the 1951 Treasury-Federal Reserve Accord, U.S. monetary policy followed a "free reserves" strategy that was essentially equivalent to setting nominal interest rates; see, for example, Davis (1971). During the late 1960s monetary policy was focused on short-term nominal interest rates directly.

2. It is difficult to be precise about when the Federal Reserve began focusing on monetary targets in an important way. Congress did not ask the Federal Reserve to announce its monetary targets in advance until 1975, but the Federal Open Market Committee started including a monetary growth target in its monetary policy directives in 1970. For evidence on the importance of monetary aggregate targets in Federal Reserve policymaking during these years, see De Rosa and stern (1977), Diggins (1978), Feige and MCGee (1979), and Lombra and Moran (1980). 
3. This section draws heavily on my earlier papers, especially Friedman (1981, 1982a); see those papers for more complete descriptions of the data and more complete sets of empirical results.

4. The three monetary aggregates all follow the Federal Reserve's new (post-1980) definitions. The reason for including bank credit is that the Federal Reserve currently includes a bank credit target, along with the targets for the monetary aggregates, in its semi-annual reports to Congress.

5. This is the specification originally made popular by the Federal Reserve Bank of St. Iouis. Its use here is intended to facilitate ready comparisons. Even so, the precise details of the specification do not matter much. For example, the standard errors for the estimation of (1) subject to no constraints at all on the $\beta$ and $\gamma$ coefficients are .00738 for total net credit, .00863 for bank credit, .00709 for Ml, .00820 for M2, .00835 for M3, and .00825 for the monetary base. Changing the lag length apparently does not matter much either.

6. The estimated $\beta$ values also look about as plausible for total net credit as for the monetary aggregates. The estimated values (and associated t-statistics) for total net credit are $.958(4.0), .541(4.0),-.097(-0.4),-.349(-2.7)$ and -.155 $(-0.6)$, with sum $.899(5.0)$. The corresponding values for $\mathrm{Ml}$, for example, are $.437(3.8), .437(5.9), .245(2.6), .043$ $(0.6)$ and $-.056(-0.5)$, with sum $1.106(6.3)$. The sum of 
coefficients is near unity in both cases, as expected, while the individual coefficients on total net credit decline more rapidly than do those on $\mathrm{MI}$ and even show one significant negative value, thereby suggesting a more complicated response pattern of income.

7. Among the most important eriticisms of the st. Louis approach have been those of Goldfeld and Blinder (1972), Sargent (1976), and Modigliani and Ando (1976). The methodology underlying the tests described below is due largely to Granger and Sims; see especially sims (1980).

8. The orthogonization procedure is

$$
\begin{aligned}
{\left[\begin{array}{ll}
\Phi_{11} & \Phi_{12} \\
\Phi_{21} & \Phi_{22}
\end{array}\right] } & =\left[\begin{array}{cc}
\Theta_{11} & \Theta_{12} \\
\Theta_{21} & \theta_{22}
\end{array}\right]\left[\begin{array}{ll}
1 & 0 \\
\lambda & 1
\end{array}\right] \\
{\left[\begin{array}{l}
\varepsilon_{1 t} \\
\varepsilon_{2 t}
\end{array}\right] } & =\left[\begin{array}{cc}
1 & 0 \\
-\lambda & 1
\end{array}\right]\left[\begin{array}{l}
\mu_{1 t} \\
\mu_{2 t}
\end{array}\right]
\end{aligned}
$$

for $\lambda=\operatorname{cov}\left(\mu_{1}, \mu_{2}\right) / \operatorname{var}\left(\mu_{1}\right)$. This orthogonalization is equivalent to placing $F$ last in the pairwise causal ordering of $\mathrm{Y}$ and $\mathrm{F}$. The alternative ordering placing $\mathrm{F}$ first, which follows from transposing the $\lambda$ (or $-\lambda$ ) and the zero elements, gives results that are close to those reported below, indicating that the arbitrarily selected ordering of the orthogonalization does not matter much here. See Friedman (1981) for the full set of results based on both orderings. 
9. Analogous simulations, showing the dynamic response of each respective $F / Y$ ratio to a $I \%$ innovation in $Y$, showed little difference from one definition of $F$ to another; see Friedman (1981).

10. The full set of results presented in Friedman (1981) showed sharply unstable relationships for other credit aggregates, including measures either narrower or broader than total net credit. Similar instability for these other credit measures appeared in simulations of the trivariate systems corresponding to those shown in the bottom half of Table 2 .

11. Analogous simulations, showing the dynamic response of each respective $\mathrm{F} /(\mathrm{X} \cdot \mathrm{P})$ ratio to a $I \%$ innovation in either $\mathrm{X}$ or $P$, showed more limited differences from one definition of $F$ to another; see again Friedman (1981).

12. An exception, which is probably not of much practical importance, is the case in which data on the aggregate are available before data on income. The data-lag case has received a good deal of attention in the literature, primarily because it is isomorphic to the more relevant case of structural economic lags; see Friedman (1975).

13. The exogeneity test results shown in Table 3 differ in several interesting respects from those based on the pre-1980 MI definition and a 1953-78 sample period in Friedman (1982a), which indicated more fully parallel roles for money and credit. For example, the F-statistics corresponding to the four-variable system shown in the bottom panel were (by 
rows, as in Table 3) $10.77 *, 2.42 * *, 2.47 * *, 2.14 * * ; 0.28$, $59.83 *, 1.35,0.55 ; 2.50 * *, 2.67 * *, 107.11 *, 0.92 ; 1.01$, 1.71, 1.95***, 161.10*. Here, in contrast to the results shown in Table 3 , both money and credit are significant in the real income equation, while neither is (individually) significant in the price equation.

14. To recall, the moving-average representation, analogous to (2), expresses all movement in each variable in terms of the history of innovations corresponding to itself and other variables in the system.

15. See again footnote 8 . The orthogonalization procedure for the four-variable system is analogous. The simple correlations of the estimated innovations (before orthogonalization) are $\rho_{X P}=$ $.58, \rho_{X M}=.33, \rho_{X C}=-.03, \rho_{P M}=.49, \rho_{P C}=-.10$ and $\rho_{M C}=-.21$.

16. See again footnote 13 .

17. Shiller (1980) has also questioned the central bank's ability to influence real interest rates. Although most economists have accepted the central bank's ability to control shortterm interest rates, at least over short time horizons and in nonpathological circumstances, doubt about the ability to control long-term interest rates is of long standing.

18. Even in the absence of any controllability at all, however, a variable could serve as a monetary policy "information variable" in the sense of Kareken et al. (1973) and Friedman (1975). 
19. See, for example, the work of Johannes and Rasche (1979, 1981) and Tinsley et al. (1981).

20. Equations of this form have become standard since the work of Davis and Shadrack (1974). As in the case of the St. Louis equations presented in Section $I$, the use of the Davis-Schadrack form here is intended to facilitate ready comparisons. An additional variable included by Davis and Shadrack, the quantity of government deposits, is omitted here and in (7) - (II) below because preliminary experimentation indicated that its coefficent was never significantly nonzero. Experimentation not reported here also indicated that the nature of the constraint imposed on the respective distributed lags had no noticeable implications for the results.

21. Interpretation of these relationships is subject to the usual caveats regarding whether they are true reduced forms; even if so, whether the underlying behavior would remain invariant to systematic changes in the conduct of policy; and whether the use of within-quarter corrections, based on incoming data, would significantly matter. Although a structural approach like that implemented in Friedman (1977) or Sivesind and Hurley (1980) would be preferable, in that it would at least address the first of these potential problems, such an effort lies beyond the scope of this paper. The results presented in Section IV below bear on the issue of withinquarter corrections. 
22. One contrast between the estimated $\delta$ values shown for credit and those shown for $M I$ in the top two panels of Table 6 is that the implied polynomial for credit has an unstable root While that for MI does not. Single-minded use of the reserves instrument to control a credit target, without any allowance for the uncertainty associated with the estimated coefficient values, would therefore lead to "instrument instability" in the sense outlined by Holbrook (1972). The relevance of this result is dubious, however, since credit would probably not be the sole intermediate target, and since the optimal policy would allow for uncertainty in the manner shown by Brainard (1967) in any case.

23. Indeed, as of the time of writing there is some debate over whether it is still doing so.

24. The $\delta$ values shown in the bottom two panels of Table 6 indicate unstable polynomials with a federal funds rate instrument for both credit and Ml. See again footnote 22 .

25. A potentially useful exercise, which lies beyond the scope of this paper, would be to compare the relative extent to which the monthly credit data and monetary aggregate data, respectively, are subject to revision.

26. In practice the bulk of the credit data is gathered from reporting by lenders. In principle, of course, the relevant information could be gathered from either lenders or borrowers. 
27. After 1977 the Federal Reserve ceased performing seasonal adjustments to its monthly credit data file. The Federal Reserve staff is currently developing a seasonally adjusted monthly credit data file that will be up to date. Once these new data are available, it will be straightforward to carry out the empirical work presented below on a current sample.

28. For example, the coefficient of variation of the ratio of quarterly "total" net credit to gross national product over 1963-77 is .016 on the basis of the raw data and .010 on the basis of the detrended data. The summary statistics for the nominal income equation (1), estimated for the 1963-77 sample period, are $\mathrm{SE}=.00762, \overline{\mathrm{R}}^{2}=.23$ and $D W=2.25$. These results are comparable to the results for total net credit (and superior to those for the monetary aggregates) for the experiments in Table 1 redone for the 1963-77 sample.

29. Use of the business sales variable, in the absence of monthIy data on the gross national product, again follows Davis and Schadrack (1974).

30. Because they tend to be more volatile than credit (or M1) on a monthly basis, $M 2$ and M3 show larger $\bar{R}^{2}$ values despite the larger standard errors.

31. As in the results based on quarterly data, the estimated $\delta$ values indicate an unstable polynomial for credit (though not MI) with a reserves instrument, and for both credit and MI with a federal funds rate instrument. 
32. See again footnote 27 . 
Brainard, w.C.

(1967) Uncertainty and the Effectiveness of Policy. American Economic Review, 57: 411-425.

Davis, R.G.

(1971) Short-Run Targets for Open Market Operations. Open Market Policies and Operating Procedures - Staff. Studies. Washington: Board of Governors of the Federal Reserve System. , and Schadrack, F.C.

(1974) Forecasting the Monetary Aggregates with Reduced-Form Equations. Monetary Aggregates and Monetary Policy. New York: Federal Reserve Bank of New York. DeRosa, P., and Stern, G.

(1977) Monetary Control and the Federal Funds Rate. Journal of Monetary Economics, $3: 217-230$.

Diggins, J.R.

(1978) A Short Term Model of Federal Reserve Behavior in the 1970s. (Ph.D. dissertation, Harvard University). Feige, E.I., and McGee, R.

(1979) Has the Federal Reserve Shifted from a Policy of Interest Rate Targets to a Policy of Monetary Aggregate Targets? Journal of Money, Credit and Banking, 11: 381-404.

Friedman, B.M.

(1975) Targets, Instruments and Indicators of Monetary Policy. Journal of Monetary Economics, 1: 443-473. 


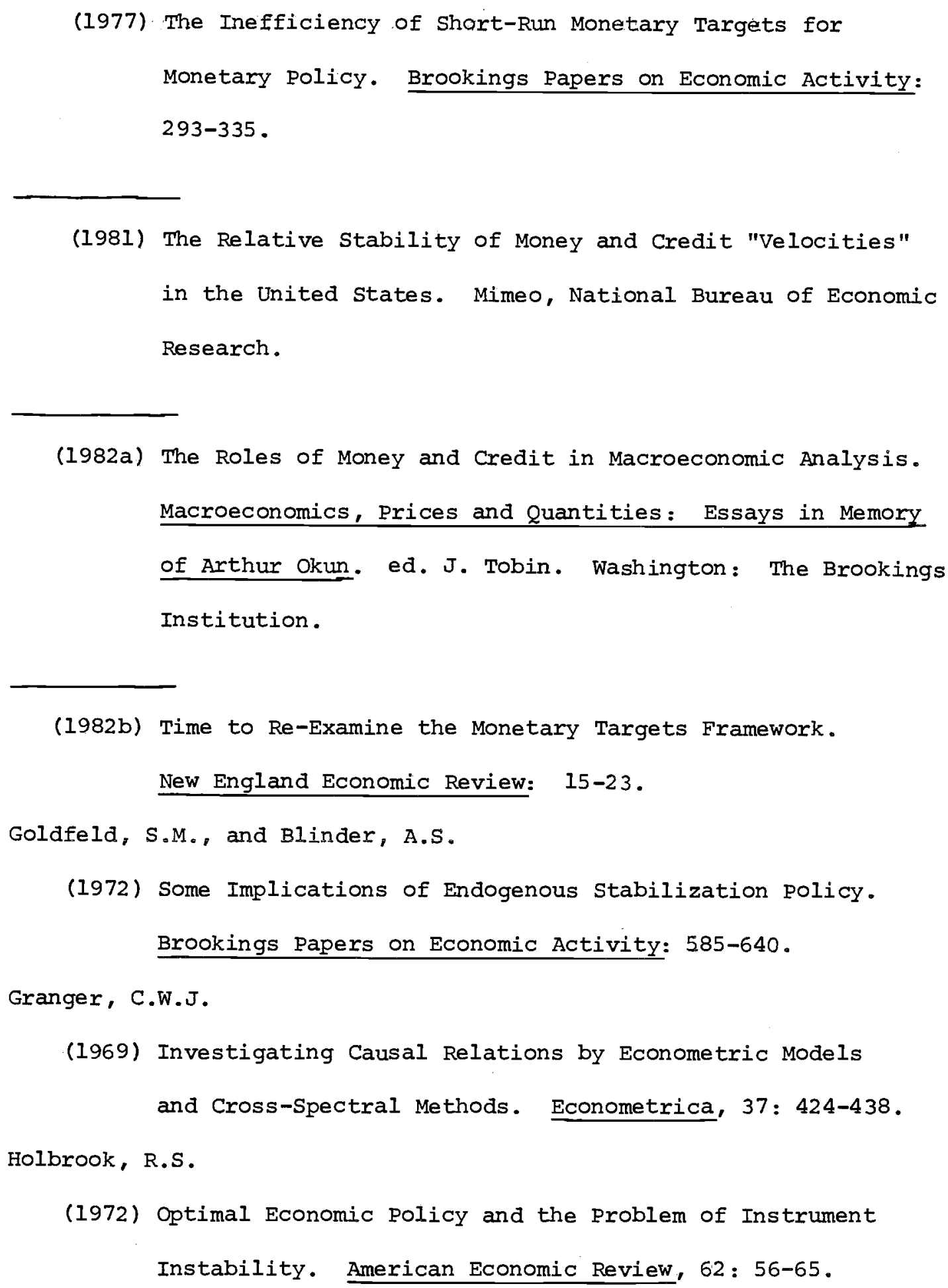

(1981) The Relative Stability of Money and Credit "Velocities" in the United States. Mimeo, National Bureau of Economic Research.

(1982a) The Roles of Money and Credit in Macroeconomic Analysis. Macroeconomics, Prices and Quantities: Essays in Memory of Arthur okun. ed. J. Tobin. Washington: The Brookings Institution.

(1982b) Time to Re-Examine the Monetary Targets Framework. New England Economic Review: 15-23.

Goldfeld, S.M., and Blinder, A.S.

(1972) Some Implications of Endogenous Stabilization policy. Brookings Papers on Economic Activity: 585-640.

Granger, C.W.J.

(1969) Investigating Causal Relations by Econometric Models and Cross-Spectral Methods. Econometrica, 37: 424-438. Holbrook, R.S.

(1972) Optimal Economic Policy and the Problem of Instrument Instability. American Economic Review, 62: 56-65. 
Johannes, J.M., and Rasche, R.H.

(1979) Predicting the Money Multiplier. Journal of Monetary Economics, $5: 301-325$.

(1981) Can the Reserves Approach to Monetary Control Really Work? Journal of Money, Credit and Banking, 13: 298-313. Kareken, J., Muench, T., and Wallace, N.

(1973) Optimal Open Market Strategy: The Use of Information Variables. American Economic Review, 63: 156-172.

Lombra, R., and Moran, M.

(1980) Policy Advice and Policymaking at the Federal Reserve. - Monetary Institutions and the Policy Process. Brunner and Meltzer (eds.) Amsterdam: North-Holland.

Modigliani, F., and Ando, A.

(1976) Impacts of Fiscal Actions on Aggregate Income and the Monetarist Controversy: Theory and Evidence. Monetarism. ed. J. Stein. Amsterdam: North-Holland.

Sargent, T.J.

(1976) The Observational Equivalence of Natural and Unnatural Rate Theories of Macroeconomics. Journal of Political Economy, $84: 631-640$.

Shiller, R.J.

(1980) Can the Fed Control Real Interest Rates? Rational

Expectations and Economic Policy. ed. S. Fischer. Chicago: University of Chicago. 
Sims, C.A.

(1972) Money, Income and Causality. American Economic Review, $62: 540-522$

(1980) Macroeconomics and Reality. Econometrica, 48 : 1-48. Sivesind, C., and Hurley, $\mathrm{K}$.

(1980) Choosing an Operating Target for Monetary Policy. Quarterly Journal of Economics, 94: 199-203.

Tinsley, P.A., von zer Muehlen, P., and Fries, G.

(1981) The Short-Run Volatility of Money Stock Targeting. Mimeo, Board of Governors of the Federal Reserve System. 